International Journal of Maternal and Child Health and AIDS (2020), Volume 9, Issue I, 93-I02

\begin{tabular}{ll}
\hline & INTERNATIONAL JOURNAL of \\
& MATERNAL and CHILD HEALTH and AIDS \\
& ISSN 216I-864X (Online) \\
& ISSN 216I-8674 (Print) \\
\hline IJMA Available online at www.mchandaids.org & DOI: 10.21 I 06 /ijma.324 \\
\hline
\end{tabular}

\title{
ORIGINALARTICLE
}

\section{Characteristics of Early Newborn Care:A Descriptive Analysis of Recent Births in Nigeria}

\author{
Comfort Z. Olorunsaiye, MPH, PhD; $\bowtie$ A-Mac Harris, MD;' Korede K.Yusuf, MBBS, MPH, PhD² \\ 'Department of Public Health, Arcadia University, Glenside, PA, USA; ${ }^{2}$ College of Nursing and Public Health, Adelphi University, Garden City, NY, USA \\ Corresponding author email: olorunsaiyec@arcadia.edu
}

ABSTRACT

Background or Objectives: The neonatal period, the first 28 days of life, is the most critical period for child survival. In 2017, 2 14,000 children in Nigeria died during the neonatal period. Newborn care practices play a key role in preventing these deaths. The aim of this study was to examine the association between delivery location and early newborn care in Nigeria.

Methods: Data from the 2013 Nigeria Demographic and Health Survey were analyzed. The main exposure variable was delivery location (home, public hospital, public health center/clinic and private hospital/clinic). The outcomes were early initiation of breastfeeding, breastfeeding support, and cord examination. We used multivariate logistic regression to estimate the odds of newborn care.

Results: We observed that the prevalence of all three outcome indicators was low.After adjusting for confounders, birth in public health facilities, compared to home birth, was associated with early initiation of breastfeeding (public hospitals: OR I.62, 95\% Cl: I.29-2.03; public health centers/clinics OR: I.28, 95\% Cl: I.02-I.6I). Breastfeeding support and cord examination were each associated with birth in public hospitals only compared to home birth (OR I.4I, 95\% Cl: I.09-I.8I and OR I.4I, 95\% Cl: I.I I-I.79, respectively).

Conclusion and Global Health Implications: Early newborn care in Nigeria was suboptimal and the quality of this care varied across delivery locations and birth attendants. Public hospitals had the most favorable newborn care outcomes. Policies and programs to enhance the quality of facility-based early newborn care and promote community-based newborn care could improve neonatal outcomes and reduce overall child mortality in resource-challenged settings.

Key words: • Newborn care $・$ Neonatal mortality $・$ Breastfeeding $\bullet$ Cord care $\bullet$ Nigeria

Copyright (C) 2020 Olorunsaiye et al. Published by Global Health and Education Projects, Inc. This is an open-access article distributed under the terms of the Creative Commons Attribution License CC BY 4.0.

\section{Introduction}

Despite the global progress in the reduction of under-five mortality, the decline in neonatal mortality has been less successful. ${ }^{1,2}$ In 2017 , of the
5.4 million under-five deaths recorded, 2.5 million deaths occurred during the neonatal period. ${ }^{2}$ The neonatal period, the first 28 days of life is the most critical period for child survival as the risk of death is highest during this time..$^{2-5}$ Most neonatal deaths 
occur in the first week of life, with approximately one million deaths each occurring on the first day and over the next six days, respectively. ${ }^{4,5}$ The leading causes of neonatal deaths are preterm birth, delivery-related complications such as birth asphyxia, infections, and birth defects. ${ }^{6}$ Most neonatal deaths occur in low- and middle-income countries with the highest burden in sub-Saharan Africa and South Asia. Children in these regions are nine times as likely to die within their first month of life compared to children in other regions. ${ }^{7}$ Nigeria, like many sub-Saharan African countries, experienced a slight decline in neonatal mortality from 2000-2017 but still accounts for the highest number of neonatal deaths in sub-Saharan Africa. ${ }^{7}$ Additionally, with 214,000 neonatal deaths in 2017 , Nigeria is second to India in the number of neonatal deaths. ${ }^{2}$

Newborn care practices play a key role in preventing neonatal deaths. ${ }^{8}$ Specifically, improving newborn care practices in the early neonatal period is correlated with reduced neonatal and underfive mortality. ${ }^{4}$ However, there is little evidence on newborn care practices in Nigeria and Sub-Saharan Africa. Newborn care practices should be adequately addressed not just because of the strong correlation with neonatal and under-five deaths, but also because the interventions addressing neonatal mortality are inherently linked to those addressing maternal and under-five death. ${ }^{4}$

The World Health Organization (WHO) recommendations for newborn care practices include initiation of breastfeeding within the first hour after birth, thermal care (drying and wrapping, skin-to-skin contact, delayed bathing), and umbilical cord care. ${ }^{3,5}$ Thermal care and cord care were reported as common practices in Nigeria. ${ }^{9}$ However, breastfeeding initiation has been reported to be delayed beyond the first hour after birth. ${ }^{10}$ These practices are critical to newborn survival, especially in resource-limited settings. Equally, these practices are highly influenced by cultural practices of parents or caregivers at home ${ }^{10}$ and location of birth, given that one-half of neonatal deaths occur at home. ${ }^{11,12}$

The objective of this study is to examine early newborn care practices in Nigeria. We explored associations between delivery location and early newborn care. We defined early newborn care as I) early initiation of breastfeeding (EIBF) (i.e. within the first hour after birth), 2) breastfeeding support (counseling and/or observation) and 3) cord examination by a health professional within two days after birth. We assessed differences in these outcomes among children born at home, and in public or private health facilities. This study fills a gap in existing knowledge on newborn care practices across various health care contexts. We extend the research on newborn care by identifying the prevalent early care practices and how these differ across delivery locations in Nigeria, a country with unacceptably high burden of neonatal and child deaths. Findings can help inform policies and programs on improving newborn care and survival, especially in resource-limited settings where the burden of neonatal and child deaths are the highest.

\section{Methods}

\section{I. Data Source and Study Sample}

Data were utilized from the 2013 Nigeria Demographic and Health Survey (DHS). The data are nationally representative, cross-sectional samples of the noninstitutionalized population and are designed to provide population estimates and indicators at the national and sub-national levels. The surveys use standard questionnaire modules, adapted to suit the context in each participating country. We used data from the women's questionnaire and included 16,504 women with a recent live birth (live birth within three years prior to the survey). We excluded women with missing data on the early newborn care practices of interest (breastfeeding initiation and support $(n=325)$, cord examination $(n=28)$ and delivery location $(n=74))$, yielding a final analytic sample of I6,077 women with recent live births.

\subsection{Study Variables}

The primary outcomes were EIBF (early breastfeeding initiation; defined as within one hour after birth); breastfeeding support (breastfeeding counseling and/or observation) and cord examination by a health professional within the first two days after birth. Each outcome measure 
was coded as I (yes) or 0 (no). The main exposure was the location of childbirth. This was a categorical variable and included home (respondent's or other), public hospital, public health center/clinic/post, or private hospital/clinic.

We included the following reproductive health care covariates: birth attendant (doctor, nurse/ midwife, auxiliary midwife/community health officer $(\mathrm{CHO})$, traditional birth attendant, or others (no one, friends, relatives)); timing of the first antenatal care (ANC) visit (none, $1^{\text {st }}, 2^{\text {nd }}$, or $3^{\text {rd }}$ trimester); and Cesarean birth (yes/no). Individual and household socio-demographic covariates included maternal age (15-19, 20-29, 30-39, 40-49 years); maternal education (none, primary, secondary, or higher); marital status (currently married/in union or never/ formerly married); household income (low-income: poorest and poor, average-income: middle, or highincome: rich and richest household wealth quintiles, respectively); area of residence (rural/urban); ethnicity (Fulani, Hausa, Igbo, Yoruba or others); parity (I, 2-4, or 5+ children); multiple birth (yes/ no); child's size at birth (very small, small, average, or large); and pregnancy wantedness (then, later, or no more).

\subsection{Statistical Analysis}

We computed weighted percentages of the coverage of newborn care practices.Additionally, we estimated three separate multivariate logistic regression models, one per outcome. First, we performed bivariate analysis to estimate the unadjusted odds of each outcome by the main exposure variable. We adjusted each model for the socio-demographic and reproductive health covariates. We generated odds ratios (OR) with corresponding 95\% confidence intervals $(\mathrm{Cl})$ for variables in each model. All tests were two-sided and conducted in Stata version 15 using the svy command to account for the complex sampling methodology. We considered $\mathrm{p}$-values $<0.05$ statistically significant.

\subsection{Ethical Approval}

Survey procedures were approved by the Nigeria Health Ethics Review Committee.The DHS Program granted us access to the dataset. The institutional review board of Arcadia University determined our study exempt.

\section{Results}

\section{I. Social and Demographic Characteristics of Women with Recent Live Births in Nigeria}

Nearly one-half of women in the study were aged 20-29 years old (48.9\%), had no education (48.1\%), and lived in low-income households (46.0\%); nearly two-thirds of the women lived in rural areas (65.1\%)

Table I: Select social and demographic characteristics of women with recent births $s^{a}$ in Nigeria, 2013 demographic and health survey

\begin{tabular}{|c|c|}
\hline Variable & Weighted \% \\
\hline \multicolumn{2}{|l|}{ Maternal age (years) } \\
\hline $15-19$ & 7.6 \\
\hline $20-29$ & 48.9 \\
\hline $30-39$ & 34.9 \\
\hline $40-49$ & 8.7 \\
\hline \multicolumn{2}{|l|}{ Highest level of education } \\
\hline None & 48.1 \\
\hline Primary & 19.0 \\
\hline Secondary & 27.0 \\
\hline >Secondary & 6.0 \\
\hline \multicolumn{2}{|l|}{ Household wealth } \\
\hline Low income & 46.0 \\
\hline Average & 20.9 \\
\hline High income & 19.1 \\
\hline \multicolumn{2}{|l|}{ Marital status } \\
\hline Married & 95.5 \\
\hline Not married & 4.5 \\
\hline \multicolumn{2}{|l|}{ Type of residence } \\
\hline Rural & 65.1 \\
\hline Urban & 34.9 \\
\hline \multicolumn{2}{|l|}{ Parity } \\
\hline $\mathrm{I}$ & 19.0 \\
\hline $2-4$ & 45.0 \\
\hline$\geq 5$ & 36.0 \\
\hline \multicolumn{2}{|l|}{ Location of birth } \\
\hline Home & 63.2 \\
\hline Public hospital & 14.5 \\
\hline Public health center/clinic & 9.0 \\
\hline Private hospital/clinic & 13.3 \\
\hline
\end{tabular}


Table I: (Continued)

\begin{tabular}{|c|c|}
\hline Variable & Weighted \% \\
\hline \multicolumn{2}{|l|}{ Birth attendant } \\
\hline Doctor & 4.2 \\
\hline Nurse/midwife & 30.2 \\
\hline Auxiliary midwife/CHO & 6.9 \\
\hline Traditional birth attendant & 20.8 \\
\hline Others & 37.9 \\
\hline \multicolumn{2}{|l|}{ Timing of first ANC visit } \\
\hline No ANC & 33.7 \\
\hline First trimester & 17.7 \\
\hline Second trimester & 40.6 \\
\hline Third trimester & 8.0 \\
\hline \multicolumn{2}{|l|}{ Cesarean birth } \\
\hline Yes & 2.2 \\
\hline No & 97.8 \\
\hline \multicolumn{2}{|l|}{ Multiple birth } \\
\hline Yes & 1.8 \\
\hline No & 98.2 \\
\hline \multicolumn{2}{|l|}{ Size of child at birth } \\
\hline Large & 44.0 \\
\hline Average & 41.0 \\
\hline Small & 10.0 \\
\hline Very small & 5.0 \\
\hline \multicolumn{2}{|l|}{ Wanted pregnancy } \\
\hline Then & 89.7 \\
\hline Later & 7.9 \\
\hline No more & 2.4 \\
\hline \multicolumn{2}{|l|}{ Ethnicity } \\
\hline Fulani & 7.9 \\
\hline Hausa & 35.2 \\
\hline Igbo & 11.0 \\
\hline Yoruba & 11.5 \\
\hline Others & 34.4 \\
\hline
\end{tabular}

(Table I). More than 6 in 10 births (63.2\%) occurred at home, $14.5 \%$ in public hospitals, $9.0 \%$ in public health centers/clinics and $13.3 \%$ in private hospitals and clinics.

\subsection{Select Newborn Care Practices in Nigeria}

About $34.3 \%$ of women initiated breastfeeding within I hour after birth (Table 2). Only $22.6 \%$ of mothers were counseled and/or observed breastfeeding
Table 2: Distribution of select early newborn care practices by country in Nigeria, 2013 demographic and health survey

\begin{tabular}{lc}
\hline Variables & $\%$ \\
\hline Breastfeeding initiation & \\
\hline Within I hour & 34.3 \\
\hline I-24 hours & 41.3 \\
\hline$>24$ hours & 24.4 \\
\hline Breastfeeding support ${ }^{\mathrm{b}}$ & \\
\hline Yes & 22.6 \\
\hline No & 77.4 \\
\hline Cord examination & 24.3 \\
\hline Yes & 75.7 \\
\hline No
\end{tabular}

during the first 2 days following birth. Similarly, only $24.3 \%$ of newborns received cord examination by a health professional during the same period.

\subsection{Predictors of Select Early Newborn Care Practices in Nigeria}

Location of childbirth was significantly associated with EIBF in all public health facilities; however, this was not the case in private facilities (public hospitals: OR: I.62, 95\% Cl: I.29-2.03; public health centers/clinics OR: I.28, 95\% Cl: I.02-I.6I; private hospitals and clinics OR: 0.97, 95\% Cl: 0.76-I.23) (Table 3). Women who gave birth in public hospitals had significantly higher adjusted odds of receiving breastfeeding support (public hospitals: OR: I.4I, 95\% Cl: I.09-I.8I) compared to women who gave birth at home; the associations were not significant for public health centers/clinics and private hospitals/ clinics. The only significant association between cord examination and location of birth was in public hospitals (OR: I.4I, 95\% Cl: I.II-I.79). Mothers whose deliveries were attended by a nurse/midwife or TBA were more likely to initiate breastfeeding within the first hour after birth compared to those attended by doctors (nurse/midwife: OR: I.30, 95\% Cl: I.0I-I.68; TBA: OR: I.47, 95\% Cl: I.06-2.05). Compared to births attended by doctors, the adjusted odds of breastfeeding support and cord examination were significantly lower among all other birth attendants. 
Table 3:Adjusted odds ratios (OR) and $95 \%$ confidence intervals $(\mathrm{Cl})$ of early newborn care in Nigeria, demographic and health survey, 2013

\begin{tabular}{|c|c|c|c|}
\hline \multirow[t]{2}{*}{ Variable } & Early breastfeeding initiation & Breastfeeding support & Cord examination \\
\hline & OR $(95 \% \mathrm{CI})$ & OR $(95 \% \mathrm{CI})$ & OR $(95 \% \mathrm{CI})$ \\
\hline \multicolumn{4}{|l|}{ Delivery location } \\
\hline \multicolumn{4}{|l|}{ Home (Ref) } \\
\hline Public hospital & $1.6 \mathrm{I}(1.28-2.03)^{*}$ & $1.41(1.09-1.82)^{*}$ & $1.43(1.12-1.82)^{*}$ \\
\hline Public clinics & $1.31(1.05-1.65)^{*}$ & $1.12(0.86-1.47)$ & I.II (0.86-I.42) \\
\hline Private hospitals/clinics & $1.08(0.85-1.38)$ & $1.23(0.95-1.60)$ & $1.27(0.99-1.63)$ \\
\hline \multicolumn{4}{|l|}{ Delivery attendant } \\
\hline \multicolumn{4}{|l|}{ Doctor (Ref) } \\
\hline Nurse/midwife & $1.39(1.09-1.78)^{*}$ & $0.69(0.54-0.89)^{*}$ & $0.72(0.56-0.91)^{*}$ \\
\hline Auxiliary midwife/CHO & $1.12(0.83-1.5 \mathrm{I})$ & $0.47(0.34-0.65)^{*}$ & $0.56(0.34-0.75)^{*}$ \\
\hline TBA & $1.47(1.06-2.05)^{*}$ & $0.39(0.27-0.55)^{*}$ & $0.47(0.34-0.65)^{*}$ \\
\hline Others & $1.22(0.88-1.68)$ & $0.38(0.27-0.54)^{*}$ & $0.43(0.3 \mathrm{I}-0.59)^{*}$ \\
\hline \multicolumn{4}{|l|}{ Maternal age (years) } \\
\hline \multicolumn{4}{|l|}{ 15-19 (Ref) } \\
\hline $20-29$ & $1.08(0.91-1.28)$ & $1.13(0.90-1.45)$ & $1.14(0.92-1.43)$ \\
\hline $30-39$ & I.II (0.90-I.36) & $1.41(1.07-1.85)^{*}$ & $1.40(1.09-1.81)^{*}$ \\
\hline $40-49$ & $1.12(0.88-1.43)$ & $1.26(0.90-1.75)$ & $1.26(0.93-1.71)$ \\
\hline \multicolumn{4}{|l|}{ Highest level of education } \\
\hline \multicolumn{4}{|l|}{ None (Ref) } \\
\hline Primary & $1.02(0.88-1.17)$ & $1.47(1.23-1.76)^{*}$ & $1.36(1.14-1.62)^{*}$ \\
\hline Secondary & $0.98(0.85-1.13)$ & $1.68(1.37-2.05)^{*}$ & $1.59(1.30-1.93)^{*}$ \\
\hline$>$ Secondary & I. $13(0.89-1.42)$ & $2.18(1.68-2.83)^{*}$ & $1.93(1.49-2.50)^{*}$ \\
\hline \multicolumn{4}{|l|}{ Household wealth } \\
\hline \multicolumn{4}{|l|}{ Low income (Ref) } \\
\hline Average & $1.24(1.06-1.44)^{*}$ & $1.28(1.04-1.56)^{*}$ & $1.21(1.00-1.47)$ \\
\hline High income & $1.39(1.17-1.66)^{*}$ & $1.86(1.49-2.32)^{*}$ & $1.67(1.35-2.06)^{*}$ \\
\hline \multicolumn{4}{|l|}{ Marital status } \\
\hline Married $($ Ref $=$ not married) & $1.12(0.92-1.36)$ & $\mathrm{I} .00(0.78-\mathrm{I} .28)$ & $1.03(0.80-1.33)$ \\
\hline \multicolumn{4}{|l|}{ Type of residence } \\
\hline Rural (Ref=urban) & $0.74(0.63-0.87)^{*}$ & $0.89(0.75-1.05)$ & $0.84(0.7 \mathrm{I}-0.99)^{*}$ \\
\hline \multicolumn{4}{|l|}{ Parity } \\
\hline \multicolumn{4}{|l|}{ I (Ref) } \\
\hline $2-4$ & $1.16(1.03-1.31)^{*}$ & $0.91(0.78-1.05)$ & $0.86(0.75-0.98)^{*}$ \\
\hline $5+$ & $1.25(1.06-1.48)^{*}$ & $0.77(0.62-0.95)^{*}$ & $0.75(0.62-0.91)^{*}$ \\
\hline \multicolumn{4}{|l|}{ Cesarean birth } \\
\hline Yes (Ref=no) & $0.38(0.28-0.53)^{*}$ & $1.44(1.03-2.00)^{*}$ & $1.34(1.00-1.79)$ \\
\hline \multicolumn{4}{|l|}{ Multiple birth } \\
\hline Yes (Ref=no) & $0.77(0.56-1.05)$ & $1.57(1.07-2.30)^{*}$ & $1.49(1.03-2.14)^{*}$ \\
\hline \multicolumn{4}{|l|}{ Size of child at birth } \\
\hline \multicolumn{4}{|l|}{ Very small (Ref) } \\
\hline Small & $0.91(0.7|-| . \mid 8)$ & $\mathrm{I} .20(0.86-\mathrm{I} .68)$ & I.18 (0.87-I.62) \\
\hline
\end{tabular}


Table 3: (Continued)

\begin{tabular}{|c|c|c|c|}
\hline \multirow[t]{2}{*}{ Variable } & \multirow{2}{*}{$\begin{array}{c}\text { Early breastfeeding initiation } \\
\text { OR }(95 \% \mathrm{Cl})\end{array}$} & \multirow{2}{*}{$\begin{array}{c}\text { Breastfeeding support } \\
\text { OR }(95 \% \mathrm{CI})\end{array}$} & \multirow{2}{*}{$\begin{array}{c}\text { Cord examination } \\
\text { OR }(95 \% \mathrm{CI})\end{array}$} \\
\hline & & & \\
\hline Average & $1.06(0.85-1.32)$ & $1.5 \mathrm{I}(1.13-2.02)^{*}$ & $1.47(1.12-1.93)^{*}$ \\
\hline Large & $1.15(0.94-1.43)$ & $1.44(1.06-1.94)^{*}$ & $1.43(1.09-1.88)^{*}$ \\
\hline \multicolumn{4}{|l|}{ Wanted pregnancy } \\
\hline \multicolumn{4}{|l|}{ Then (Ref) } \\
\hline Later & $0.73(0.62-0.87)^{*}$ & $1.34(1.12-1.61)^{*}$ & $1.35(1.13-1.61)^{*}$ \\
\hline No more & $0.67(0.50-0.90)^{*}$ & $1.45(1.06-2.01)^{*}$ & $1.51(1.13-2.02)^{*}$ \\
\hline \multicolumn{4}{|c|}{ Timing of first ANC visit } \\
\hline \multicolumn{4}{|c|}{ No ANC (Ref) } \\
\hline First trimester & $\mathrm{I} .05(0.88-\mathrm{I} .24)$ & $4.85(3.80-6.18)^{*}$ & $3.80(3.05-4.73)^{*}$ \\
\hline Second trimester & $1.19(1.02-1.39)^{*}$ & $3.76(3.02-4.68)^{*}$ & $3.09(2.55-3.74)^{*}$ \\
\hline Third trimester & $1.31(1.09-1.58)^{*}$ & $3.04(2.27-4.07)^{*}$ & $2.49(1.88-3.3 I)^{*}$ \\
\hline \multicolumn{4}{|l|}{ Ethnicity } \\
\hline \multicolumn{4}{|l|}{ Fulani (Ref) } \\
\hline Hausa & $\mathrm{I} .03(0.78-1.35)$ & $0.86(0.60-1.23)$ & $0.91(0.66-1.26)$ \\
\hline Igbo & $0.97(0.7 \mathrm{I}-1.33)$ & $0.65(0.45-0.95)^{*}$ & $0.72(0.51-1.01)$ \\
\hline Yoruba & $0.84(0.62-1.14)$ & $1.78(1.23-2.56) *$ & $1.74(1.25-2.43) *$ \\
\hline Others & $1.73(1.3 \mathrm{I}-2.28) *$ & $0.98(0.70-1.37)$ & $1.01(0.75-1.36)$ \\
\hline
\end{tabular}

\section{Discussion}

This study examined the characteristics of early newborn care and the relationship between delivery location and early newborn care among children aged 0-36 months in Nigeria. We are not aware of any study from sub-Saharan Africa which evaluated cord examination by a health professional as a part of early newborn care. We extend existing research on newborn care by assessing the relationship between delivery location of various types and ownership (namely home, public hospital, public health centers/ clinics, and private hospitals/clinics) and early newborn care in Nigeria. Previous studies combined all delivery facilities irrespective of ownership. ${ }^{13}$ Previous studies also did not stratify public facilities into the subtypes hospitals and health centers/clinics. ${ }^{13,14}$

In the current study, almost two-thirds of women had a home birth, and we observed that the prevalence of all three indicators of early newborn care was low. Women who delivered at a public hospital were more likely than their counterparts who delivered at home to initiate breastfeeding early, receive breastfeeding support, and have their newborn's cord examined by a health professional. There were no significant differences in all three indicators among births in private hospitals compared to home births. Other factors associated with early newborn care included delivery attendant, household wealth, maternal education, parity, and timing of the first ANC visit.

EIBF provides colostrum or "first milk", which contains important nutrients and antibodies, helps fight disease-causing agents such as bacteria and viruses. ${ }^{15}$ Studies have found that the initiation of breastfeeding within the first hour after birth may prevent up to $20 \%$ of neonatal deaths. ${ }^{16,17}$ Despite the benefits of ElBF, our study found that the prevalence of EIBF in Nigeria (34.3\%) was lower than the WHO target of $50 \%$ by the year 2025. ${ }^{18}$ This rate is the second-lowest in West Africa and also one of the lowest in sub-Saharan Africa. ${ }^{19} \mathrm{We}$ observed that less than one-fourth of women were counseled and/or observed breastfeeding during the first 2 days following birth. Likely factors responsible for the delayed initiation of breastfeeding in Nigeria 
include the belief that the baby is not hungry, both mother and baby need to rest after delivery to regain strength, some mothers' inability to lactate immediately, performance of rituals/prayers, and the cultural practice of discarding the colostrum. Colostrum is discarded because it is believed to be dirty milk, "like pus," and can harm the baby. ${ }^{20}$

In our study, only about one-fourth of newborns' cords were examined by a health professional within two days after birth. This suboptimal rate is concerning because the umbilical cord may be one of the common portals of entry for invasive pathogenic bacteria, ${ }^{21}$ which account for approximately 700,000 neonatal deaths annually. ${ }^{22}$ Although there are studies on cord care practices in sub-Saharan Africa, ${ }^{10}$ we found no research on the prevalence of cord examination and its determinants. The dearth of research on cord examination may be due to lack of data since the DHS just recently started collecting data on this topic in some countries. We hope that our findings and increased availability of data will stimulate research in this vital area of neonatal health.

Home births remain relatively common in Nigeria; $63 \%$ of mothers in this study delivered their babies at home. From recent research, about $53 \%$ of births in sub-Saharan Africa take place at home. ${ }^{14}$ Analysis of these home births by country shows Nigeria has one of the highest rates. Home births in sub-Saharan Africa are rarely assisted by skilled birth attendants (SBA), ${ }^{14}$ and have a higher likelihood of perinatal mortality. ${ }^{23}$ We also noted that childbirth location was related to EIBF, breastfeeding support, and cord examination. EIBF was more likely among mothers who delivered in public facilities compared to mothers who delivered at home with or without a SBA. Using 2013 NDHS, Berde and Yalcin ${ }^{13}$ found that Nigerian mothers who delivered in a health facility were more likely to initiate breastfeeding early compared to mothers who delivered at home. However, the investigators dichotomized place of delivery as "home" and "health facility." Our study presents a new finding as we categorized delivery location differently and observed that the positive effect of location on EIBF occurred among public facility births only. Additionally, we found that among public facility births, EIBF was more favorable in public hospitals than public health centers/clinics. Adoption of the Baby-Friendly Hospital Initiative (BFHI) by the public facilities might contribute to the higher likelihood of EIBF in those delivery locations. The BFHI was adopted in Nigeria in 1992 in response to UNICEF and WHO efforts to ensure that all maternity centers support breastfeeding. ${ }^{24,25}$ This initiative may also partly explain our finding of higher adjusted odds of breastfeeding support among women who had their babies in public hospitals compared to home births. Facility delivery serves as a point of contact with a healthcare professional who may provide advice and support on breastfeeding during the crucial time around birth, ${ }^{26}$ and discourage adverse breastfeeding practices or advice received from other sources. ${ }^{27}$

Further, babies born in public hospitals compared to home births had a higher likelihood of having their cord examined by a health professional. This result is not unexpected; mothers who deliver in public hospitals are more likely to be attended by SBAs than those who have their babies at home. Surprisingly, we did not observe a significant difference in the likelihood of receiving breastfeeding support and newborn cord examination among births in public health centers/clinics and private hospitals/clinics compared to home births. A possible explanation is that typically there is a higher proportion of lower-skilled health workers in public clinics and private hospitals than in public hospitals. For instance, public hospitals employ only formally trained nurses/ midwives for clinical services, while an estimated $27 \%$ of the clinical workforce in private hospitals comprises auxiliary nurses/midwives. ${ }^{28}$ An auxiliary nurse/midwife is a person who acts as a health care assistant after informal and on-the-job training in health facilities. ${ }^{28}$ Another possible explanation for our findings could be the main difference between public hospitals and public clinics. Public hospitals include mostly tertiary and highly specialized institutions that represent the highest level of healthcare services in Nigeria, ${ }^{28}$ while the public clinics constitute primary healthcare facilities that provide healthcare to the population at the most basic levels and are more likely to lack highly-skilled personnel. ${ }^{28}$

We also observed that birth attendant at delivery was a determinant of early newborn care. Compared to doctors, other delivery attendants were less 
likely to provide breastfeeding support and cord examination. However, mothers whose deliveries were attended by nurses/midwives were more likely to practice EIBF than those attended by doctors. These findings may indicate that the skills or the roles of delivery attendants in achieving favorable early newborn care practices vary. A previous study on low- and middle-income countries suggests that SBA care is positively associated with favorable breastfeeding practices. $^{29}$ Further, in support of this argument, we found that as the professional cadre of birth attendants decreased, the odds of breastfeeding support and cord examination also decreased. Lower-cadre birth attendants may be less able to provide breastfeeding support and cord examination probably because of the nature of their pre-or in-service training.

Surprisingly, we noted that women whose deliveries were attended to by TBAs had the highest adjusted odds of EIBF compared to all other birth attendants. This finding might be due to residual confounding. Research has shown that infants delivered by TBAs are less likely to have adverse perinatal outcomes such as preterm birth and severe hyperbilirubinemia compared with infants delivered in hospitals. ${ }^{30,31}$ Thus, it is possible that newborns delivered by TBAs may be able to commence breastfeeding early. Further research, preferably qualitative, is required to understand this intriguing observation.

\section{I. Strengths and Limitations}

Our study has several strengths. First, the data were from a nationally representative survey; therefore, our findings are generalizable to Nigeria. Second, we stratified delivery location into subtypes that enabled us to evaluate the correlation among private facilities, public hospitals, and public health centers/clinics with early newborn care. Third, to our knowledge, ours is the first study to investigate newborn cord examination as part of early newborn care in Nigeria. This study, however, has some limitations. We did not stratify home births into SBA and non-SBA, which would allow for the identification of a possible moderating effect of SBAs on early newborn care practices among home births. However, women's self-report of the indicator 'SBA' has been shown to have low validity. ${ }^{32}$ We also did not account for cultural practices that may affect the study outcomes. For example, a common cultural practice in Nigeria prevents newborns from being taken outside the home during the first 40 days after birth; this could affect care-seeking behavior. However, these variables were not included in the data.

\section{Conclusion and Global Health Implications}

Despite the aforementioned limitations, our study has implications for global health policy and practice. Stakeholders need to intensify efforts to ensure proper implementation and evaluation of interventions to improve breastfeeding practices, particularly among mothers who deliver their babies at home or in a private health facility. All SBAs need to be adequately trained on providing optimal newborn care, including cord examination. Because most deliveries in Nigeria occur at home, community-based breastfeeding promotion and early newborn care programs should be prioritized. These programs should target factors that are negatively associated with newborn care practices. Further, there is a need to improve the overall quality of newborn care in private and lower-level public health facilities through in-service training and supervision.

In conclusion, our work revealed suboptimal coverage of early newborn care practices in Nigeria. This study provides evidence that the adjusted odds of achieving these three indicators of newborn care practices are associated with delivery location, with public hospitals having the most favorable outcomes. Stakeholders and policymakers may utilize our findings to identify and evaluate interventions that can improve early newborn care and increase child survival in Nigeria.

\section{Compliance with Ethical Standards}

Conflicts of Interest: The authors have no conflicts of interest. Financial Disclosure: The authors have no financial disclosures. Funding/Support: This study was not funded. Ethics Approval: The institutional review board of Arcadia University determined our study exempt. 


\section{Key Messages}

- The prevalence rates of early initiation of breastfeeding, breastfeeding support and cord examination were suboptimal.

- Women who delivered at a public hospital were more likely to initiate breastfeeding early, receive breastfeeding support, and have their newborn's cord examined than their counterparts who delivered at home.

- Mothers whose deliveries were attended by nurses/midwives were more likely to practice early breastfeeding initiation and less likely to report breastfeeding support and newborn cord examination than those whose deliveries were attended by doctors.

\section{References}

I. Lawn JE, Blencowe H, Oza S, You D, Lee AC, Waisaw P, Lalli M, Bhutta ZA, Barros AJ, Christian P, et al. Every newborn: progress, priorities, and potential beyond survival. Lancet. 20।4;384:189-205.

2. Hug L, Alexander M, You D, Alkema L, \& UN Interagency Group for Child Mortality Estimation. National, regional, and global levels and trends in neonatal mortality between 1990 and 2017, with scenario-based projections to 2030: a systematic analysis. The Lancet Global Health. 2019;7(6):e7I0-20.

3. Langlois ÉV, Miszkurka M, Zunzunegui MV, Ghaffar A, Ziegler D, Karp I. Inequities in postnatal care in low-and middle-income countries: a systematic review and meta-analysis. Bulletin of the World Health Organization. 20I5;93:259-70G.

4. World Health Organization (WHO). United Nations Children's Fund (UNICEF). Every Newborn: An action plan to end preventable deaths. Geneva: World Health Organization. Published 2014. Available at https://apps.who.int/iris/bitstream/ handle/I 0665/I 27938/978924 I507448_eng.pdf. Accessed May 14, 2019.

5. World Health Organization (WHO). Postnatal Care for Mothers and Newborns. Highlights from the World Health Organization 2013 Guidelines. Published 2013. Available at https://www.who.int/ maternal_child_adolescent/documents/postnatalcare-recommendations/en/.Accessed May II, 2019.
6. Darmstadt GL, Bhutta ZA, Cousens S, Adam T, Walker $\mathrm{N}$, de Bernis L: Evidence-based, costeffective interventions: how many newborn babies can we save?. Lancet. 2005;365(9463):977-988.

7. United Nations Children's Fund (UNICEF). United Nations Inter-Agency Groups for Child Mortality Estimation (UN IGME): Levels \& trends in child mortality: Report 2018. Available at https:// www.unicef.org/publications/index_103264.html. Accessed May II, 2019.

8. Onalo R. Neonatal hypothermia in sub-Saharan Africa: A review. Nigerian Journal of Clinical Medicine. 2013;16(2):129-138. DOI: 10.4103/III93077.110120.

9. Adejuyigbe EA, Bee MH, Amare Y, Omotara BA, Iganus RB, Manzi F, Shamba DD, Skordis-Worrall J, Odebiyi A, Hill ZE. "Why not bathe the baby today?": A qualitative study of thermal care beliefs and practices in four African sites. BioMed Central: Pediatrics. 2015; 15(1):156-162.

10. Bee M, Shiroor A, Hill Z. Neonatal care practices in sub-Saharan Africa: a systematic review of quantitative and qualitative data. Journal of Health, Population and Nutrition. 2018;37(1):9-20.

II. Bazzano AN, Felker-Kantor E, Eragoda S, Kaji A, Horlick R. Parent and family perspectives on homebased newborn care practices in lower-income countries: a systematic review of qualitative studies. British Medical Journal Open. 2019;9(4):e02547I.

12. Belizán JM, McClure EM, Goudar SS, et al. Neonatal death in low- to middle-income countries: a global network study. American Journal of Perinatology. 2012;29(8):649-656.

13. Berde AS, Yalcin SS. Determinants of early initiation of breastfeeding in Nigeria: A population-based study using the 2013 demographic and health survey data. BioMed Central:Pregnancy and Childbirth. 20 I6;16:32-40.

14. Bergamaschi N, Oakley L, Benova L. Is childbirth location associated with higher rates of favourable early breastfeeding practices in sub-Saharan Africa? Journal of Global Health. 2019;9(I):010417.

15. United Nations Children's Fund (UNICEF). Improving breastfeeding, complementary foods, and feeding practices. Publication date not listed. Available at https://www.unicef.org/nutrition/index breastfeeding.html.Accessed on August 15, 2019.

16. NEOVITA Study Group.Timing of initiation, patterns 
of breastfeeding, and infant survival: Prospective analysis of pooled data from three randomised trials. Lancet Global Health. 2016;4(4):e266-75.

17. Debes AK, Kohli A,Walker N, Edmond K, Mullany LC. Time to initiation of breastfeeding and neonatal mortality and morbidity: a systematic review. BioMed Central: Public Health. 2013; I3(S3):SI 9.

18. World Health Organization (WHO). Global nutrition targets 2025. Publication date not listed. Available at http://www.who.int/nutrition/globaltarget-2025/en/.Accessed on August 15, 2019.

19. Issaka Al, Agho KE, Renzaho AM. Prevalence of key breastfeeding indicators in 29 sub-Saharan African countries: A meta-analysis of demographic and health surveys (2010-2015). British Medical Journal Open. 20I7;7(I0):e014I45.

20. Davies-Adetugbo AA. Sociocultural factors and the promotion of exclusive breastfeeding in rural Yoruba communities of Osun State, Nigeria. Social Science \& Medicine. 1997;45( I): I I3-125.

2I. Mullany LC, Darmstadt GL, Khatry SK, et al. Topical applications of chlorhexidine to the umbilical cord for prevention of omphalitis and neonatal mortality in southern Nepal: a community-based, clusterrandomized trial. Lancet. 2006;367(95/4):910918pmid: 16546539.

22. Liu L, Johnson HL, Cousens S, et al. Global, regional, and national causes of child mortality: An updated systematic analysis for 2010 with time trends since 2000. Lancet. 20 I 2;379(9832):2 I 5 I-2 I 6 I.

23. Chinkhumba J, De Allegri M, Muula AS, Robberstad B. Maternal and perinatal mortality by place of delivery in sub-Saharan Africa:A meta-analysis of populationbased cohort studies. BioMed Central: Public Health. 2014;14:1014.

24. Oche MO, Umar AS, Ahmed H. Knowledge and practice of exclusive breastfeeding in Kware, Nigeria. African Health Sciences. 20 I I; I I (3):5 I8-523.

25. United Nations Children's Fund (UNICEF). The Baby-Friendly Hospital Initiative. Available at https:// www.unicef.org/nutrition/index_24806.html. Accessed on August 5, 2019.

26. Khan SM, Speizer IS, Singh K, Angeles G, Ay N, Danso $\mathrm{T}$, et al. Does postnatal care have a role in improving newborn feeding? A study in 15 subSaharan African countries. Journal of Global Health. 2017;7:020506. doi: 10.7189/jogh.07.020506.

27. Khanal V, Lee AH, Karkee R, Binns CW. Prevalence and factors associated with prelacteal feeding in western Nepal. Women and Birth. 2016;29(I):I2-I7.

28. Woodman SB, Toriola M, Chatterji M, Kinnan C, Jackson J. A census of private health facilities in six states of Nigeria. 2014.Abt Associates Inc.; Bethesda, MD.

29. Oakley L, Benova L, Macleod D, Lynch CA, Campbell OMR. Early breastfeeding practices: Descriptive analysis of recent demographic and health surveys. Maternal \& Child Nutrition. 20 I8; |4(2):e I 2535.

30. Nkwo PO, Lawani LO, Ezugwu EC, lyoke CA, Ubesie AC, Onoh RC. Correlates of poor perinatal outcomes in non-hospital births in the context of weak health system:The Nigerian experience. BioMed Central: Pregnancy Childbirth. 20 I4; |4:34I-350.

31. Olusanya BO, Inem VA, Abosede OA. Infants delivered in maternity homes run by traditional birth attendants in urban Nigeria: A communitybased study. Health Care for Women International. 20I I;32(6):474-49I.

32. Blanc AK, Warren C, McCarthy KJ, Kimani J, Ndwiga C, RamaRao S. Assessing the validity of indicators of the quality of maternal and newborn health care in Kenya. Journal of Global Health. 2016;6(I):010405-17. 